\title{
The Scope of e-Learning: Expanded Horizons for Life-Long Learning
}

\author{
Dr Elspeth McKay and Professor Bill Martin \\ RMIT University, Melbourne, Australia
}

\author{
elspeth.mckay@rmit.edu.au bill.martin@rmit.edu.au
}

\section{Abstract}

The purpose of this paper is to open a discourse on the broad scope of e-Learning. The authors provide an overview of a much larger debate-mindful that the consequential topics are far reaching. The discussion first deals with the need to utilize meta-knowledge within the context of Web-based learning providing the background for the process of scoping e-Learning. The e-Learning phenomenon we experience today provides courseware designers with an opportunity to revisit all the fundamentals of instructional science involving learning theories and human performance. In setting the scene for the reader, it is useful to drill into the background issues of the digital learning context. It will be shown that the scope of e-Learning is more comprehensive than the commonly accepted issue of electronic delivery of instructional/learning materials. Wise use of the technologies can provide the leverage human beings require at this point for expanding their horizons for life-long learning.

Keywords: meta-knowledge, knowledge management, human-computer interaction, Web-based instruction

\section{Background}

The journey of life is truly fascinating. Human beings travel great distances—some travels are short, some are longer; however there are none so long as the quest for life-long learning. As humans mature, their sense of time develops. This journey involves us in seeking ways to become proficient in a variety of tasks, and gaining intellectual satisfaction in a range of content specific areas. Notwithstanding the apparent common knowledge that advances in information technology together with societal change have pushed forward an acceptance that e-Learning has created new paradigms for training and education (Khan, 2001); there are more sceptical authors who take cognisance of the déjà vu effect of these new paradigms (Spitzer, 2001; Rosenberg, 2001).

For over three decades, it has been possible to learn many things using a computer. In the early days of human-computer interaction (HCI), interest in the merits of e-Learning was manifest amongst the educational researchers of the time (Pask \& Scott, 1972). In general, attitudes and feelings towards computer based training (CBT) have taken shape over time. In the beginning, CBT packages only offered a static type of interaction (www.smartforace.com, 2001) whereby the learner was given practically no opportu-

Material published as part of these proceedings, either on-line or in print, is copyrighted by Informing Science. Permission to make digital or paper copy of part or all of these works for personal or classroom use is granted without fee provided that the copies are not made or distributed for profit or commercial advantage AND that copies 1) bear this notice in full and 2) give the full citation on the first page. It is permissible to abstract these works so long as credit is given. To copy in all other cases or to republish or to post on a server or to redistribute to lists requires specific permission from the publisher at Publister@intommingscience.org nity to engage in a two-way instructional/learning session.

A problematic aspect of this type of learning context is the lack of agreement over the nomenclature. For instance: there has been a range of terminology applied to HCI within a learning/training framework. Some of the terms have been better known than others, and appear to be interchangeable 
The Scope of e-Learning

(Gery, 1987). For example: computer assisted instruction (CAI), computer aided learning $(C A L)$, computer managed education( $C M L)$, computer based training (CBT), computer enhanced teaching (CEH), computer mediated development (CMD) and computer interactive study (CIS).

In those earlier days and of relevance to this paper, the most noticeable misuse of the terminology occurred in relation to the mixing of the terms education, training, instruction, and learning. These days however, these terms are all seen to have very different meanings. Possibly this realization has become more pronounced since the advent of Web-based learning/training. Some scholars use the term eLearning without a second thought. Be that as it may, how many agree on the meaning, much less fully understand how comprehensive and complex the concept of e-Learning really is.

Over time technology has improved to such an extent that courseware developers appear to have unlimited capacity to develop seamless instruction/learning training/education opportunities. To appreciate the scope of e-Learning this discussion begins with a short comment on Web-based learning. Three aspects of the Web-based learning context are covered. In the first, a meta-knowledge processing model is proposed as a mechanism for identifying the complex nature of electronic courseware authoring. The second aspect suggests that instructional technology has altered our perceptions of learning. The third deals with the issue of coming to grips with differences between online training and knowledge management.

\section{Web-Based Learning Context}

Confusion abounds. There are so many different voices in the literature. Where is the common ground? What can we be sure of? For instance: on the one hand some researchers agree on the importance of the constructivism and social cognition (Hung \& Nichani, 2001); while there is the equal but opposite view knowledge can be engineered through intelligent agents (Lopez, 2001).

There is now a considerable literature on the topic of computer-based instruction and designing online learning systems. Nevertheless it will only be through targeted research that it will be known with any certainty whether Web-based learning gives rise to a new type of learning dissonance. It has been proposed that converged theoretical paradigms that underpin particular digitised or context-mediated learning systems are forcing learners into new ways of thinking (McKay, 2000a). In a sense, the combination of theoretical perspective and electronic communications technology fosters a mentality that Web-based learning will supply a learning-on-demand, or a just-in-time approach.

The Web-based learning context should be about providing open, flexible and distributed learning environments. However, as will be seen, without adequate learning management processes embedded within the courseware, this type of distributed learning experience will remain just that, distributed.

The granularity of the Web-based learning context is extensive. To understand this we turn to instructional science to provide the framework for our thinking.

\section{Meta-Knowledge Processing Model}

There is limited evidence in the research literature that directly links instructional strategies to individual differences in preferred learning modes (McKay,2000a). On the surface, it might appear to be a common goal on the part of courseware developers, to move beyond individual instruction to individualized instruction as first described by Ausburn \& Ausburn (1978). Nonetheless, for this trend to be established, there must be clear indications of consideration given to designing instruction that caters for cognitive style differences.

There has been relatively little research into this type of customized courseware. For instance: there has been a limited amount of investigation into the interactive effect of a learner's preference for cognitive 
mode, the information processing elements (Bower, 1994) of the task requirements, and instructional strategies.

In the past, the Aptitude Treatment Interaction (ATI) model was thought an appropriate research methodology (Ausburn \& Ausburn, 1978). However, ATI is a hypothesis, which suggests that the most effective learning materials, or methods, are dependent on measurable learner characteristics, or aptitudes, such as imagery or verbal abilities.

Nowadays there are effective methodologies put forward to measure individuals' cognitive differences (Riding \& Cheema, 1991). It should be noted that with the proliferation of online courseware development, there is still a need for researchers to pay attention to the interaction of cognitive style and instructional format as identified (McKay \& Garner, 1999). It has been shown that visually oriented learners do not necessarily perform best with visual instructional format (Middleton, 1999; McKay, 2000a).

More work is needed to investigate whether dissimilar cognitive styles will interact differently, resulting in superior performance by learners with one cognitive style under one condition of an e-Learning instructional strategy, and by learners of another cognitive style under a different e-Learning condition of instructional strategy. The complexity of the electronic media cannot be overstated. Sound research designs limit the generalisation of treatment effects, thereby producing robust research results, rather than findings that are broad and all-encompassing (Snow, 1974; Merrill, 1994; (McKay, 2000b). To understand the complexities of the e-Learning domain it is necessary to clarify each component involved. Firstly, there is a conceptualized relationship between learner and task (Figure 1). It is not too difficult to imagine the possibility of an interactive effect of a mismatched learner's capacity to achieve a particular task and the instructional format. For instance: a learner with some form of visual impairment and an instructional medium, which involved only screen-based instructional material.

Figure 1: Conceptualized Relationship Between Learner and Task

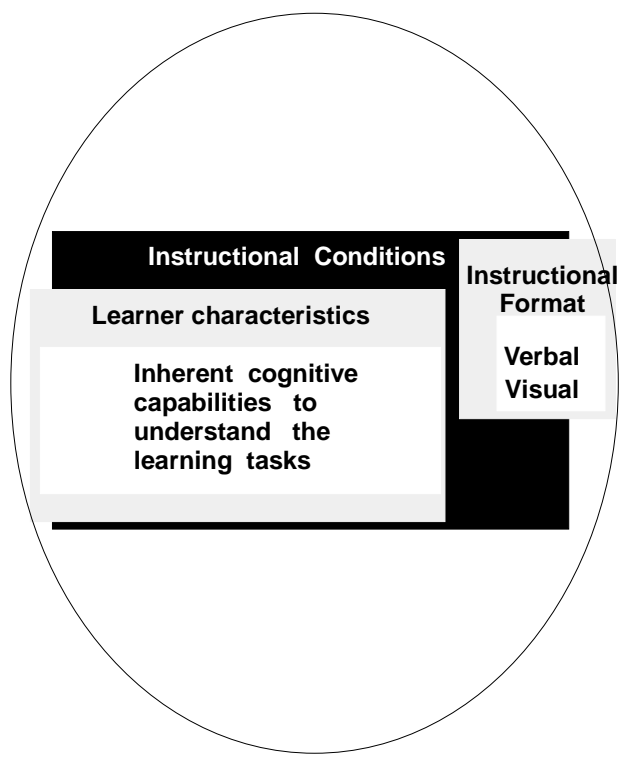

Secondly, to know how to effectively draw on the characteristics of the learner and their probability to acquire the skills/knowledge to complete a particular learning event, a mechanism is needed - $a$ key - to unlock the instructional strategies. Figure 2 depicts such a key as the Meta-Knowledge Processing Model, which can be used by courseware designers (McKay, 2000c). The components of this model are interactive in the sense that they can be correctly identified in isolation from one another. Each component can be designed and installed to create an instructional system with the ability to respond with a socially acceptable learning context for each novice-leaner. 


\section{Figure 2: Meta-Knowledge Processing Model}

The Meta-Knowledge Processing Model articulates the complexity of the e-Learning delivery environment. The Method of Delivery Transfer Agent directs the Instructional Conditions according to the re-

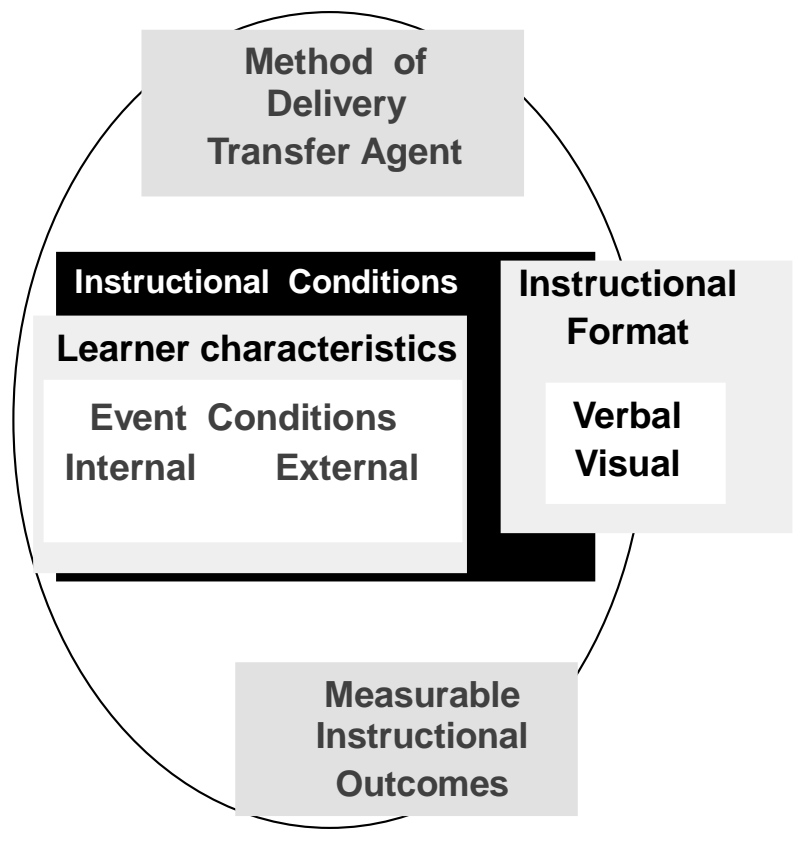

sults of the Learner Characteristics (cognitive style) and Event Conditions (complexity of processing the learning material), and the Measurable Instructional Outcomes. Directions for choice of Instructional Format are given by the Method of Delivery Transfer Agent (or learner).

Too often novice-learners are left to stumble their way through electronic courseware. The means now exist to deliver customised learning environments. In reality though, generic instructional formats often provide too much information, or too little. The meta-knowledge relating to an individual's likely perception of instructional strategies should however, bring courseware construction into the realm of truly thoughtful instructional systems' development.

Courseware authoring involves the instructional designer in a complex pedagogical process. First, there must be some understanding of how learners deal with the learning content. Next, is the recognition of the interactive effect of an individual's knowledge processing and cognitive style. Finally, the designer needs to be aware of how the dynamics of the Meta-Knowledge Processing model (see Figure 2) impact on intelligent tutoring tools.

Becoming familiar with each component of the e-Learning context can only enhance the quality of courseware design. The change may take some time however, as the rush to enter the online delivery game is well underway, regardless of the apparent lack of industry standards.

Wait though - how much is understood about the impact that technology has had on learning opportunities? Can it be said that new wave has emerged - where any type of electronic learning is best?

\section{Metamorphosis}

It would seem from listening to educationalists talking about their preparations for e-Learning, that the approach to online learning has undergone some kind of mystical transformation. From all accounts, unless learning materials are online they should be thrown out with the bath water (so to speak). However, listening to novice-learners talking about their experiences with Web-based learning products; it is 
pretty apparent there is quite a considerable gap in their expectations. The task ahead for courseware designers is to fill this gap.

Moreover, the so called Web-based learning industry will only succeed when the human element is realized (Spitzer, 2001). For instance: difficulties arising through access equity will need to be addressed. Currently there are few newly created products entering the market place that are designed to help individuals with particular physical disabilities engage with Web-based learning. These haptic interface technology devices provide kinaesthetic sensations through tactile feedback mechanism. Examples of this type of computer access aid are: haptic mice, joysticks, and touch sense devices (Bussell, 2001).

It would seem that a common fault with much of the discourse on e-Learning to date is that it remains limited to the HCI aspects. This tendency narrows the focus of the debate leaving out one of the most important issues relating to courseware design. It is essential to look beyond software/hardware management and deal with the difficulties relating to maintaining the integrity of the learning activities per se. Of particular importance is to deal effectively with the information that is central to each particular eLearning event.

This leads on to another key point, which is - how much is understood about the need to accommodate different instructional outcomes? Can it be said that Web-based material is equipped to deal with this issue - where any type of human performance that can be measured and evaluated electronically is best?

\section{Management}

So is the debate really about event management? If this is the case, a major portion of material written about e-Learning does not make this distinction clear enough. Perhaps the confusion relates to the effects of distributed cognition (Salomon, 1993) that has occurred over time. There is a risk of losing the richness of the e-Learning phenomenon if our comprehension is deferred to the literal translation. In other words, anything that is online (computerized), and involves digital technology, or can be described as electronic delivery of learning experience, will be considered e-Learning. Consequently, if courseware designers misjudge the perils of distributed cognition in relation to e-Learning, their courseware will reflect nothing more than an electronic version of the printed version.

Instead there should be considerable discussion on the wider translation of the term e-Learning. One author describes e-Learning in terms of the need to differentiate the learning event as between training and knowledge management (Rosenberg, 2001). Furthermore, enduring courseware should entail instructional strategies which are clear on the why to do it, and not just the how.

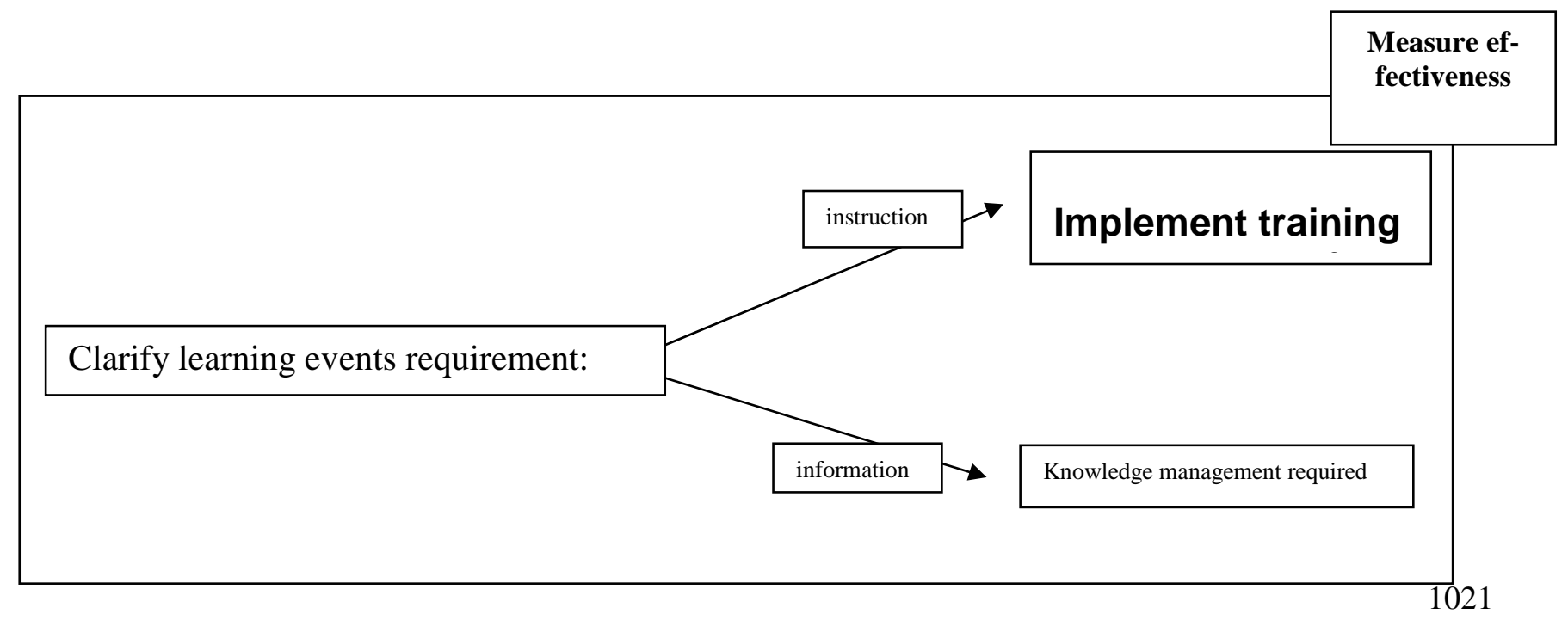




\section{Figure 3: Online training vs. knowledge management}

To this effect any learning requiring instruction belongs within the training domain, while informational requirements require a knowledge management approach. Courseware designers should first, examine the learning goals and expected performance outcome; second, decide on an instructional strategy to achieve the instructional objectives. The last but not at all the least important element, a measurement strategy must be installed to measure the effectiveness of the event. The challenge is to identify and distinguish between the need for instruction (online training) and information (knowledge management); and to understand how they work in tandem (Rosenberg, 2001).

In order to illustrate the finer granules of the debate on how to scope e-Learning, attention must turn towards the age old pursuit of knowing how to look at the different aspects of knowledge itself. This part of the discussion is just the tip of the tip of the proverbial iceberg. Knowledge features in a myriad of formats across a wide range of literatures, and is heavily contextual, the following five short sections will clarify the term knowledge, and the wider concept of knowledge management. These sections will involve: a definition from an instructional science perspective, types of formal and expressive knowledge, the knowledge construction process, and finally an educational perspective on knowledge management.

This contextual dimension extends not just to the subject or professional context or to specific organisational settings, but also to individual circumstances. One person's knowledge may be another person's information. Indeed this distinction between information and knowledge continues to be a feature of the relevant literatures.

However, before fully understanding how to define types of knowledge, it is necessary to differentiate between the basic concepts of information and knowledge. One definition that involves both concepts holds that "information is a flow of messages, while knowledge is created and organized by the very flow of information, anchored on the commitment and beliefs of its holder" (Nonaka, 1994). No doubt this debate will occupy researchers for quite some time.

\section{Knowledge defined}

As regards knowledge per se, categorizations within the mainstream management literature include knowledge that is:

- embodied: action oriented and often knowledge how

- embedded: residing in systematic routines

- embrained: dependent on conceptual skills and cognitive abilities

- encultured: through the achievement of shared understandings

- encoded: information conveyed by signs and symbols, (Blackler, 1998:71-72)

However, almost all researchers emphasise the importance of two core kinds of knowledge, namely tacit knowledge and explicit knowledge. Knowledge, learning and information are intrinsically dependant. Instructional systems rely on the analysis of learning content (or specific knowledge requirements) within a domain of information (Tennyson \& Cocchiarella, 1986).

Knowledge has been identified by the instructional science paradigm as concrete or declarative (knowing the specific facts and rules), and abstract or procedural (knowing how to apply declarative knowledge in new situations) (Gagne, 1985). More recently, it was proposed that there was enough evidence from linguistics and psychology to conclude that people construed many concepts in terms of metaphor; and called for more research to see if, when and how, certain concepts were metaphorically represented (Gibbs, 1996). 
Researchers have refined their attitude towards the relationship between knowledge and learning since the 1960's. For instance: a comprehensive schema acts as a basis for classifying types of learning; "Knowledge is 'information stored' - it is something an individual possesses. Either he has it, or he has not - a go/no-go quality. Individuals differ in the quantity of knowledge that they possess " (Romiszowski, 1981:267).

Web-based knowledge research offers an opinion that "knowledge is the product of a learning activity in which the learner, based on experience acquired through cognitive activities such as perception, interpretation, and analysis, assimilates and accommodates new information into his or her cognitive structure in accordance with the environment as he/she understands it and in collaboration with other people" (Kang \& Byun, 2001:48).

However almost all researchers from the field of learning to organisational change, place emphasis on two (apparently) distinct categories which are explicit knowledge and tacit knowledge.

\section{Explicit or expressive knowledge:}

One example of this category would be where an engineer conveys her knowledge of product design through drawings and specifications, thus making what she knows explicit (von Krogh, Ichijo \& Nonaka, 2000:6). The relative ease with which such knowledge can be identified, captured, processed and communicated renders it particularly convenient for use in instructional systems.

\section{Tacit or informal knowledge:}

Whereas some knowledge can be expressed on paper or captured in database systems other kinds are tied to the senses, to skills in bodily movement, individual perception, physical experiences, rules of thumb and intuition. This tacit knowledge is often difficult to describe to others, let alone to capture and employ (von Krogh et al., 2000:6)

\section{Knowledge construction/creation process:}

Just as there is a recognized need to discern the differences between information and knowledge, it is important to look at ways in which knowledge is developed. Knowledge construction involves two dimensions, individual knowledge construction (information acquisition, information transformation, and knowledge construction) and collaborative knowledge construction (a shared information interactivity process that cannot be separated from the socio-cultural context in which a person exists) (Kang \& Byun, 2001). In the latter case, a well-placed catalyst can elicit favourable responses during online discussions. However the facilitation must be planned (Berge \& Muilenburg, 2001).

Further research is needed on the development of integrated learning environments that operate within and between communities of learners, where support for both appropriating and negotiating knowledge can take place. The notion of community-based learning is not new (Suzuki, 2000). However, a major challenge of this decade will be to extend and refine the process to the point where e-Learning as part of that process becomes transparent to the participants.

It is also important to emphasize that this human-centred process represents a construction of reality rather than something that is true in any abstract or universal fashion (von Krogh et al., 2000:6). Furthermore, the actual creation of organization knowledge can be depicted as a series of five main steps: Sharing tacit knowledge, creating concepts, justifying concepts, building a prototype and cross levelling knowledge (von Krogh et al., 2000:7). 
The Scope of e-Learning

\section{Knowledge management:}

A major drawback of the widespread interest in knowledge management is a continuing dissatisfaction with an imprecision in terminology and the conflicting perceptions of various groups with an interest in the field. Knowledge management can mean different things to different people. At the broader organisational and management level, it has to do with the knowledge needs of the enterprise and with structures, strategies and processes for exploitation of the knowledge resource (above all human expertise and know how) and associated technologies. Seen from a computer science perspective perceptions of knowledge management could involve artificial intelligence (AI) and knowledge representation in domain ontologies and enterprise models, the use of intelligent agents and of computer-mediated communications.

This said, it is possible to make too much of such distinctions in that a combination of approaches to the problems of knowledge management will be found to operate in practice. This point can be illustrated with recourse to one of the many definitions of knowledge management that are available. Knowledge management can be defined as:

Formalisation and access to experience, knowledge and expertise that create capabilities, enable superior performance, encourage innovation and enhance customer value (Beckman, 1997).

This definition is applicable to the activities of both the organisational and technological schools of knowledge management and for present purposes fits neatly into an e-learning context. In an e-learning context the central considerations will remain human, social and organisational in nature, while increasingly facilitated by a range of technological developments, not least with the emergence of a growing array of knowledge management tools. What distinguishes this emerging class of technologies from existing data and information management tools is their ability to complement the cognitive abilities of human beings (Shariq, 1998:12) Elsewhere these tools have been defined as technologies which enhance and enable knowledge generation, codification and transfer. (Ruggles 1997:2) and as a spectrum from transaction processing systems, training and learning tools, analytical and measuring tools to those designed to assist innovation and knowledge creation (Binney, 2001)

However bringing together various types of knowledge in an electronic format is only half the problem solved. The current challenge facing researchers and those working with emerging e-Learning platforms is to make available this type of captured learning/instructional expertise in a manner that is accessible to others (Stoyanova \& Kommers, 2001; McKay, 2001). There is a risk that responses to this challenge perhaps coloured by past experience with static and unresponsive learning system, will be inadequate or insufficient.

Having proposed that when thinking of e-Learning, the need is to understand the relationship between information and knowledge; the final part of this discussion moves on to look more closely at e-Learning per se. It will be seen that the concept of e-Learning may take on a different meaning over time. However, until there is a more informed attitude towards the effect of technology on learning, there will continue to be a type of eCooking pot effect.

\section{e-Learning Scoped}

Currently there are many academic discussions on the wider terminology surrounding the context of eLearning. For instance: see http://ifets.ieee.org/maillist.htm. No doubt when opinions have matured, a new term will emerge to represent this experiential learning paradigm.

A full decade ago there was a belief that computer assisted learning (CAL) would only be possible once intelligent or expert systems were in place (Gery,1987). The authors of this paper propose that now the knowledge management voice is included in the Web-based learning scenario; it may appear that this de- 
bate has travelled full circle. Be that as it may, it is becoming more acceptable to question our reliance on technology as an effective educational medium.

Attention will now turn to alternative ways to view the meaning of a single letter; that is the use of $e$ as a kind of universal prefix. Discussion will uncover non-standard approaches to the definition of the electronicness associated with the notion of e-Learning. Although there are many conceptual events involved within a learning technology framework that begin with the letter e; three are chosen here to highlight otherwise forgotten aspects of HCI and learning.

\section{Experience}

In a sense, e-Learning represents a form of experiential awareness. By watching this debate unfold it soon becomes apparent that the notion of e-Learning varies from person to person. So what is happening here? Should e-Learning be regarded as nothing more than an electronic learning tool. After all, this seems to be the perception of the business community. Learning becomes embedded in the workplace through an implied notion from the Vygotskian School of thinking involving communities-of-practice (Hung, 2001), learning communities where collaborative learning can optimise a shared e-Learning environment (Stoyanova \& Kommers,2001; Sharpe, Hu, Crawford, Gopinathan, Moo \& Won, 2001).

Furthermore, the conceptual divide that operated between vocational and formal educational outcomes is breaking down (Wheeler, 2001). In appreciation of the power of business drivers such as profitability, industry training consultants know only too well that e-Learning should offer a contextual variety (Bagley, 2001) with time, place, finer informational type detail only if required, simulation, and community support (Rosenberg, 2001). Therefore a number of computer mediated learning networks have emerged showing how diverse learning experiences can involve previously opposed environments. Again although the assumption might be that such experiences are enriched or facilitated by technology, not everyone holds this view.

Therefore it is a mistake to take a literal meaning of the term. It can be said that e-Learning does not mean that technology is necessarily added to the process (Rosenberg, 2001).

\section{Extended}

e-Learning means experiential learning events that incorporate continuation opportunities from the actual learning event into an ongoing process - hence the notion of life long learning. Learners value programmes that deliver options to move on from the initial learning event to encounter wider opportunities where they can succeed in transferring the newly acquired tasks to new situations (Rosenberg, 2001). And again, there are questions as to the existence of a role for technology. e-Learning does not mean extended technological solutions to broaden the range of learning media (McKay, 2001).

\section{Expanded}

e-Learning means the construction of experiential learning events which expand into every aspect of daily life. Consider how often for example, consumers may seek out some type of special instruction for a new household product - like programming the remote control for a television set, or how to use a new microwave oven. There are many such examples of training needs for specific tasks and these opportunities arise constantly. The desire for different types of learning experiences is unlimited.

Finally, e-Learning does not mean concentration only on the current offerings.

In short, there are times when a comfortable fit is noticeable between the instruction/learning strategies and learner expectations. Dissonance may result when the context is not correct. 
The Scope of e-Learning

For instance: there are times when people need just the information about particular events requiring the application of knowledge management strategies. While there will be others when they expect to be shown exactly how to acquire the particular skills - requiring training through instructional strategies. Herein lies a very important distinction between two completely different e-Learning contexts.

\section{Summary}

This paper was written to add voice to the growing awareness of the tidal wave of opinion on technological learning tools. There is huge interest in all things electronic. In some quarters Web-based courseware is proving to be effective for corporate training, while in others there is concern for the pace of change expressed by teachers in the school system and academics in the higher education sector. Furthermore, eLearning is gaining the attention of industry and the education sectors alike. Perhaps this trend has contributed to the awareness that social cognition should also be recognized as a legitimate context for teaching and learning. The new millennium appears to have blown in a new wind; with it is emerging a renewed focus on the age-old pursuit for knowledge about knowledge.

There are many innovative programs under development (Wheeler, 2001). However, will such ventures as community learning to live up to expectations (Winer, Rushby, \& Vazquez-Abad, 1999)? Courseware developers are facing a new challenge. Their challenge is to understand how instruction and informational needs work in tandem (Rosenberg, 2001). The meta-knowledge process model proposed in this paper could be an aid to learning system developers. In the meantime, the following questions are worth asking:

How long should the scoping process for e-Learning last? How long before there is a common realization that the term e-Learning is nothing more than another piece of techno-jargon? How long before there is a realization that the Web-based learning context involves as many components outside the current techno-idiosyncratic framework, as within information technology - that knows no bounds, and truly extends the learning journey through time and space?

\section{References}

Ausburn, L. V., \& Ausburn, F. B. (1978). Cognitive styles: Some information and implications for instructional design. Educational Communications and Technology Journal, 26 , 336-354.

Bagley, C. A. (2001). Types of e-Learning . Stillwater, MN: The Technology Group.

Beckman, T (1997), A methodology for knowledge management, (International Association of Science and Technology for Development (IASTD) AI and soft computing conference, Banff, Canada,)

Berge, Z. L., \& Muilenburg, L. (2001). Designing discussion questions for online, adult learning. Educational Technology, 40 (5), 53-56.

Binney, D., (2001),“The knowledge managements spectrum: Understanding the KM landscape,” Journal of Knowledge Management, 5, 1, 33-42.

Blackler, F., N.Crump and S.McMcDonald (1998), Knowledge, organizations and competition, In, G.von Krogh, J.Roos and D.Kleine (Eds.) Knowing in Firms: Understanding, Managing and Measuring Knowledge (London, Sage Publications, 6786.

Bower, G. H. (1994). A turning point in mathematical learning theory. Special Issue: The centennial issue of the psychological review. Psychological Review, 101(2) (April), 290-300.

Bussell, L. (2001). Haptic interfaces: Getting in touch with web-based learning. Educational Technology, 41 (3), $27-32$.

Gagne, R. M. (1985). The Conditions of Learning: And the theory of instruction (4th ed.). New York: Holt/Rinehart/Winston.

Galbreath, J. (2001). Knowledge management technology in education: An overview. Educational Technology, 40 (3), $28-33$. 


\section{McKay \& Martin}

Gery, G. (1987). Making CBT Happen: Prescriptions for successful implementation of computer-based training in your organization . New York: Harper \& Row.

Gibbs, R. W. (1996). Why many concepts are metaphorical. Cognition, 61 (3 December), 309-319.

Hannum, W. (2001). Knowledge management in education: Helping teachers to work better. Educational Technology, 41 (3), 47-49.

Hung, D. (2001). Design principles for web-based learning: Implications from Vygotskian thought. Educational Technology, 41 (3), 33-41.

Hung, D., \& Nichani, M. (2001). Constructivism and e-Learning: Balancing between the individual and social levels of cognition. Educational Technology, 41 (3), 40-44.

Kang, M., \& Byun, H. P. (2001). A conceptual framework for a web-based knowledge construction support system. Educational Technology, 41 (4), 48-53.

Khan, B. H. (Ed.). (2001). Web-based Training . New Jersey: Educational Technology Publications.

Lewin, A. Y., \& Stephens, C. V. (1992). Designing post-industrial organization: Theory and practice. In G. P. Huber \& W. H. Glick (Eds.), Organization Change and Redesign: Ideas and Insights for Improving Managerial Performance . New York: Oxford University Press.

Lopez, A. M. J. (2001). Knowledge engineering and education. Educational Technology, 41 (3), 45-49.

McKay, E. (2000a). Instructional Strategies Integrating the Cognitive Style Construct: A Meta-Knowledge Processing Model (Contextual components that facilitate spatial/logical task performance): Doctoral Dissertation (Computer Science and Information Systems): An investigation of instructional strategies that facilitate the learning of complex abstract programming concepts through visual representation. Deakin University, Waurn Ponds, Geelong, Australia.

McKay, E. (2000b). Measurement of cognitive performance in computer programming concept acquisition: Interactive effects of visual metaphors and the cognitive style construct. Journal of Applied Measurement, 1 (3), 257-286.

McKay,E (2000c November 21-24).Towards a Meta-Knowledge Agent: Creating the context for thoughtful instructional systems, Paper for ICCE 2000 ( $8{ }^{\text {th }}$ International Conference on Computers in Education/International Conference on computer-Assisted Instruction 2000, Taipei, Taiwan. Advanced Research in Computers and Communications in Education, Learning Societies in the New Millennium: Creativity, Caring \& Commitments, S.Shwu-ching Young, J.Greer, J.Maurer, Yam San Chee (Eds.), National Tsing Hua University, Taiwan, Vol:1,200-204.

McKay, E. (2001, August 6-8). Collaborative Learning Through Versatile Representations in Asynchronous Learning Transactions via the WWW (Panel Chair Paper), Collaborative Context-Mediated Experiential Learning Through Asynchronous Learning Networks. Paper presented at the International Conference on Advanced Learning Technologies (ICALT 2001): Issues, Achievements, and Challenges. T.Okamoto, R.Hartley, Kinshuk, J.P.Klus (Eds.), Madison, Wisconsin. IEEE Computer Society. 483-487.

McKay, E. (2001). Cognitive Skill Acquisition Through a Meta-Knowledge Processing Model. Interactive Learning Environments. Vol:10 No:3.

McKay,E. \& Garner,B.J. (1999, November 4-7).The complexities of visual learning: Measuring cognitive skills performance. Paper presented at the $7^{\text {th }}$ International Conference on Computers in Education (ICCE'99), Chiba, Japan. Advanced Research in Computers and Communications in Education, New human abilities for the networked society, G.Cumming, P.Okamoto \& L.Gomez (Eds.), IOS Press: Amsterdam, Vol:1,208-215.

Merrill, M. D. (1994). Instructional Design Theory . New Jersey: Educational Technology Publications.

Middleton, C. A. (1999, January 5-8). Asynchronous computer conferencing in the MBA classroom. Paper presented at the Hawaii International Conference on System Sciences, Hawaii.

Nonaka, I. (1994). A dynamic theory of organizational knowledge creation. Organizational Science, 5 (1), 14-37.

Nonaka, I. (1995). The Knowledge-Creating Company .: Oxford University Press.

Okamoto, T., Kayama, M., \& Cristea, A. (2001, August 6-8). Panel-3, Collaborative context-mediated experiential learning through asynchronous learning: Panelist Paper No:3. Collaborative learning support knowledge management for asynchronous learning networks. Paper presented at the IEEE International Conference on Advanced Learning Technologies: Issues, Achievements, and Challenges (ICALT 2001), Issues, Achievements, and Challenges. T.Okamoto, R.Hartley, Kinshuk, J.P.Klus (Eds.), Wisconsin, USA. IEEE Computer Society: pp.490-491.

Pask, G. , \& Scott , B. C. E. (1972). Learning strategies and individual competence. International Journal Man-Machine Studies, 4, 217-253. 
The Scope of e-Learning

Riding , R. , \& Cheema , I. (1991). Cognitive styles - an overview and integration. Educational Psychology, 11 (3\&4), 193215.

Romiszowski, A. J. (1981). Designing Instructional Systems . United Kingdom: Kogan Page.

Rosenberg, M. J. (2001). e-Learning: Strategies for delivering knowledge in the digital age . New York: McGraw-Hill.

Ruggles, Rudi L. (1997), Tools for knowledge management: An Introduction, In, Knowledge management tools, Ed by R. Ruggles, Butterworth Heinemann, Boston, 1-8

Salomon, G. (Ed.). (1993). Distributed Cognitions: Psychological and educational considerations . Cambridge: University Press Syndicate.

Shariq, Syed Z. (1998), Sense making and artifacts: an exploration into the role of tools in knowledge management, Journal of Knowledge Management, 2,2, December, 10-19.

Sharpe, L., Hu, S., Crawford, L., Gopinathan, S., Moo, S. N., \& Wong, A. F. L. (2001). Multipoint desktop videoconferencing as a collaborative learning tool for teacher preparation. Educational Technology, 40 (5), 61-63.

Snow, R. E. (1974). Representative and quasi-representative designs for research on teaching. Review of Educational Research, $44,265-293$.

Spitzer, D. L. (2001). Don't forget the high-touch with the high-tech in distance learning. Educational Technology, 41 (2), 51 55.

Stoyanova, N., \& Kommers, P. (2001, 22-24 March). Learning effectiveness of concept mapping in a computer supported problem solving design. Paper presented at the Euro-CSCL 2001, Maastricht ISBN 90-097-9.

Suzuki, M. (2000). The international university, Japan: A 25-year experiment in restructuring university education. In R. Miller (Ed.), Creating Learning Communities: Models, Resources, and New Ways of Thinking About Teaching and Learning (pp. 80-89). Brandon, VT: The Foundation for Educational Renewal, Inc.

Tennyson, R. D. , \& Cocchiarella , M. J. (1986). An empirically based instruction design theory for teaching concepts. Review of Educational Research, 56 , 40-71.

Toffler, A. (1990). Powershift: Knowledge, Wealth and Violence at the Edge of 21st Century . New York: Bantam Books.

Von Krogh,G., K.Ichijo \& I.Nonaka (2000). Enabling Knowledge Creation: How to Unlock the Power of Tacit Knowledge and Release the Power of Innovation. Oxford, Oxford University Press.

Wheeler, L. (2001). Learning network models - A Practitioner's view .

Winer, L. R., Rushby, N., \& Vazquez-Abad, J. (1999). Emerging treands in instructional interventions. In H. Stolovitch \& E. Keeps (Eds.), Handbook of Human Performance Technology (pp. 867-893). San Francisco: Jossey-Bass.

www.smartforace.com. (2001). Advanced Web Authoring: CGI and PERL.

\section{Biographies}

Elspeth McKay is a Postdoctoral Research Fellow (e-Learning) at the School of Business Information Technology, RMIT University, Australia. She holds a PhD in Computer Science and Information Systems, a Graduate Diploma of Applied Science (Instructional Design), a Graduate Diploma of Education (Computer Studies), and a Bachelor of Business, with distinction (Business Information Systems). Her doctoral thesis breaks new ground for effective learning from multimedia with innovative approaches to visual instruction. This research identified that not all individuals cope effectively with graphical learning. Elspeth's research clearly identifies the complexity of the visual learning environment, and outlines prospects for customising e-Learning shells, based on ontological requirements. The prospect of customising e-Learning shells tailored dynamically to the requirements of individual learners has stimulated contemporary research into knowledge mediation, and the associated ontological strategies, of actual learning contexts with Web-enabled asynchronous learning frameworks. Elspeth's work is of benefit to educators, electro-communications engineers, and computer scientists.

Bill Martin is Professor and Director of Research in the School of Business IT at RMIT University Melbourne. Originally coming from an information science background and formerly Head of Information 
Management at both The Queens University of Belfast and RMIT, Bill has pioneered the study of knowledge management in Australia and is a frequent speaker on the subject at national and international conferences. He supervises a growing cadre of research students in the field and has conducted research into aspects of knowledge management in both the public and private sectors and in metrics for knowledge. He is currently researching links between knowledge management and electronic business. 